International Journal of Social Science And Human Research

ISSN(print): 2644-0679, ISSN(online): 2644-0695

Volume 04 Issue 03 March 2021

DOI: 10.47191/ijsshr/v4-i3-09, Impact factor-5.586

Page No : 277-288

\title{
The Relationship Between the Critical Factors for Knowledge Managementin Supply Chain Efficiency Amol's Kalleh Dairy Company
}

\author{
Seyedeh Malihe Mohammadi Takami \\ Faculty of Management, Department of Industrial Management, Islamic Azad University, Tehran, Iran
}

\begin{abstract}
Organizations that operate in a variable and complex, competitive environment are continually looking for a sustainable competitive advantage. In this regard, knowledge management is one of the most critical factors affecting the success of organizations. Relying on knowledge and knowledge management, organizations can make more reasonable decisions and achieve sustainable development. Therefore, knowledge management is one of the most influential and essential factors in comprehensive development and gaining a more significant market share. This study's primary purpose was to investigate the relationship between critical aspects of knowledge management on Kale Amol Dairy Products Company's supply chain productivity. Five main factors of organizational strategy, organizational structure, knowledge team, knowledge map, and knowledge audit were used as independent variables to achieve this goal. The research method was a correlation, and data collection tools were library and internet resources. The statistical population consisted of high and middle-class managers and staff members involved in knowledge management and supply chain in Amol Calais Dairy Products Company, of which 58 were. Chang china et al. standard questionnaire was used to measure the variables, and SPSS software was used to analyze the statistical

data.

Descriptive statistics were used for the frequency of data. The Pearson correlation test was used to determine the relationship between variables, and the Friedman test was used to prioritize the variables. After data analysis, it was found that there is a relationship between all independent variables and supply chain productivity. The knowledge map variable had the highest and organizational strategy variable with the lowest relationship with the dependent variable among independent variables.
\end{abstract}

\section{INTRODUCTION}

Knowledge management is one of the most exciting and challenging issues of management science in the new millennium. Its scope, application, and use have been expanded and opened as an interdisciplinary field in managerial texts. Knowledge management is not a new concept; perhaps many of us have managed knowledge without understanding it. But law enforcement of these activities and having a plan for its implementation is a new issue that was considered in the late 20th century. Knowledge management is a unique and valuable approach and other commercial and competitive strategies, so organizations were thinking about implementing knowledge management programs to benefit from its potential benefits (Darroch et al., 2010). In the present era, labour, raw materials or capital are not the primary resources, but knowledge is central. In organizations, physical and mental capitals are valued and considered wealth. Subjective worth consists of human capital and knowledge capital that effective interaction and integration of these two types of mental capital are mandatory in maximizing productivity. Therefore, establishing different systems without the attention and recognition of knowledge management in organizations leads to its use in organizations is not evident and does not have its necessary efficiency. The combination of two essential categories of supply chain management and knowledge management leads them as a powerful tool to improve the deficiencies in the system, and this leads them to improve the weaknesses in the system except by adequately recognizing the knowledge management and examining the role and position. It is not possible in organizations (Akhavan \& et al., 2009). This has made knowledge management one of the most critical competitive resources for any organization. Many believe that companies that can gain knowledge and reach the experimental stage as quickly as possible will be more successful in a competitive market. On the other hand, inter-corporate competition has lost its importance and competition between supply chains to provide maximum value to the customer has been emphasized (Hult et al., 2007). It can be concluded that using the concept of value chain leads to the formation of an integrated look at different activities and tasks, and consequently, the organization's resources. This helps to consider and evaluate the organization's resources for the advantages of the organization. Since the value chain is different for different enterprises, so if a company can adequately manage and manage 


\section{The Relationship Between the Critical Factors for Knowledge Management in Supply Chain Efficiency Amol's Kalleh Dairy Company}

the value-generating activities, then it can calculate the impact of each exercise in the production phases and take action to eliminate or develop a specific training with full knowledge of the current situation and future outcome. Usually, a company's value chain is connected to other companies' value chain and is a larger chain member. The value chain approach in analyzing intra-organizational activities is a useful tool in recognizing strengths and weaknesses and making decisions about any of these activities (Akhavan \&

Jafari, 2006).

Supply chain management in today's industrial environment is a new management method. Supply chain management is a critical strategy that directly impacts organizations' success in today's highly competitive business environment. With the development of supply chain management, its theme has also changed. Traditional supply chains emphasized cost and factors such as material and component flows, information flows, and financial flows. But in today's world, the market needs to respond faster than before, and traditional factor management is not responsive to chains' current needs. The key to survival in today's world has a competitive advantage over competitors.

On the other hand, productivity is essential for competition. Therefore, productivity is a crucial topic in today's world. The supply chain as a feature of today's world is no exception. Various factors and tools are known for supply chain productivity. One of these tools is knowledge management (Akhavan \& et al., 2009).

Today, supply chains and tangible resources and assets are also focused on intangible assets such as knowledge. Intangible resources can create a competitive advantage. In general, the term "intangible resources" is used to cover the suffering of a wide range of factors such as fame, supply chain configuration, knowledge and information of employees, and the organization's culture. Dyer and Hatch looked at knowledge sharing as a source of competitive advantage in the supply chain. Since business activities have moved from the organization level to the supply chain level, maintaining a competitive advantage by building strong relationships with employees, customers, and upstream and downstream suppliers and partners is the challenge facing managers. A suitable

knowledge management strategy can help achieve this goal ( $\mathrm{Wu}, 2008)$.

There are many articles on strategies, techniques, technologies, and infrastructures for the supply chain's design and development. Still, very few of them deal with knowledge management in the supply chain. On the other hand, it is necessary to have a systematic and measured study on knowledge management's critical success factors. Organizations need to be aware of the factors that affect the success of knowledge management. Not considering important necessary factors will probably hinder the organization's efforts to realize its interests fully. Therefore, considering knowledge management as one of the tools of supply chain productivity, it investigates the critical factors of knowledge management success and their effect on supply chain productivity (Wang, 2008).

\section{SUPPLY CHAIN}

All activities related to the flow and conversion of goods from raw material (extraction) to delivery to the end consumer and information flow related to them are included. In general, the supply chain is a chain that provides for all activities associated with the flow of goods and the change of materials, from the preparation of raw materials to the delivery of final goods to the consumer.

There are also two streams of information about the flow of goods and the flow of financial resources and credits (Wong, 2005).

\section{DEFINITION OF SUPPLY CHAIN MANAGEMENT}

Different researchers and authors have provided different attitudes and definitions of the supply chain. Some have limited the supply chain in the relationship between buyer and seller, which focuses solely on first-class purchasing operations in an organization. By this definition, the supply chain includes all first, second, third category suppliers... would be. Such an attitude towards the supply chain will only analyze the supply network. The third view is porter's value chain attitude, in which the supply chain includes all the activities needed to deliver a product or serve the end customer. With the approach mentioned above to the supply chain, construction and distribution functions are added to the chain as part of the flow of goods and services. With this view, the supply chain consists of three procurement areas, production and distribution (Marwick, 2009). The brief and comprehensive definitions that can be provided from the supply chain and supply chain management are as follows: The supply chain includes all activities related to the flow and conversion of goods from raw material (extraction) to delivery to the end consumer and information flow related to them (Sotriakoa, 2004). In general, the supply chain is a chain that includes all activities related to the flow of goods and the change of materials, from the preparation of raw materials to the delivery of final goods to the consumer. There are also two streams of information about the flow of goods and the flow of financial resources and credits (Tiwana, 2007). Supply chain management is a combination of art and science to improve access to raw materials, manufacturing products or services, and transfer them to the customer. Manufacturing activities in the supply chain is the production and supply of the product. For effective management of the supply chain, suppliers and customers must work together in a coordinated and coordinated way to coordinate and communicate information and dialogue. This means the rapid flow of information among customers and suppliers, distribution agency, and transportation systems enable some companies to create many supply chains (Dalkr \& Kimiz, 2005). Suppliers and customers must have the same goals. Suppliers and customers must have mutual trust. Customers trust their suppliers 


\section{The Relationship Between the Critical Factors for Knowledge Management in Supply Chain Efficiency Amol's Kalleh Dairy Company}

in the quality of products and services. Besides, suppliers and customers should share in supply chain design to achieve common goals and facilitate communication and information flow. Some companies control their supply chain by general control using ownership and integration of all different components along the supply chain, from supplying materials and services to delivering the final product and serving the customer. But even with this type of organizational structure, various activities and operational units may be uncoordinated. The company's organizational structure should focus on coordinating multiple activities to achieve its overall goals (Broadberry et al., 2006).

There is a three-dimension in supply chain management. These three steps are: 1. Intra-functional coordination (managing activities and processes within the scope of a company's support duties) 2. Coordination of inter-functional activities such as coordination between supporting activities and mali, support and tu lead, support and marketing (as they are done among the company's performance fields.

3. Coordination of interagency activities of supply chain between companies that are legally separate within the channel Product flow is a different factor among these dimensions is the amount of control that the manager has on the product flow to achieve coordination (Fernandez et al. 1, 2008).

\section{MAIN PROCESSES OF SUPPLY CHAIN MANAGEMENT}

Supply chain management has three main processes:

Information Management

Logistics Management

Relationship Management

1. Information management: Today, the role, importance and position of information is evident to all. Proper circulation and proper transfer of information make processes more efficient and easier to manage. In the discussion of the supply chain, as stated above, the importance of coordination in activities is critical. This point is also right in discussing information management in the chain, information systems management and information transfer. Coordinated and appropriate information management among partners will increase speed, accuracy, quality and other aspects. Proper management of information will lead to more coordination in the

chain. In general, in the supply chain, information management will be useful in various sectors, some of which are as follows: Logistic management (transfer, displacement, processing and access to logistic information for integration of transportation, ordering and construction processes, order changes, production timing, logistics programs and storage operations) Exchange and processing of data between partners (such as the exchange and processing of technical information, orders, etc.): data collection and processing for analysis of the process of resource detection and evaluation, selection and development of suppliers, collection and processing of supply and demand information, etc. To predict market trends and future conditions of supply and demand, create and improve relations between partners.

If it is found, information management and supply chain information systems can be useful on much internal decision-making of different parts of the supply chain, which indicates the high importance of this component in supply chain management.

2. Logistics management: In the analysis of manufacturing systems (such as the automotive industry), the logistics issue of the logistics sector of the supply chain. This section includes all physics activities from raw material preparation to final product including transportation activities, storage, production timing, etc. It consists of a relatively large part of supply chain activities. The logistics range is the flow of materials and goods and the focus of supply chain activities, which relationships and information are supporting tools for improvement activities. Interestingly, if a list of logistics-related concepts is prepared and categorized, they can be categorized into three groups: supply-oriented, producer-oriented and distributor.

3. Relationship Management: The factor that guides us to the end of the discussion and perhaps the essential part of supply chain management is managing relationships in the supply chain because of its construction and form. Relationship management has a tremendous impact on all areas of the supply chain and its performance level. In many cases, the information and technology systems needed for supply chain management activities are easily accessible and can be completed and operated in a relatively short period. But many of the early failures in the supply chain are the effect of the low transfer of expectations and expectations and the result of the behaviours that occur between the parties involved in the chain. The most critical factor for successful management of the supply chain is the reliable relationship between partners. The partners have mutual trust in each other's capabilities and operations. In short, in developing any integrated supply chain, faith and trust among the partners and a reliable plan are critical and essential elements for achieving success (Gatora, 1995/Imam, 2002).

\section{RESEARCH OBJECTIVE}

What are the critical factors of knowledge management in Kale Amol Dairy Products Company's supply chain, and what is related to efficiency, effectiveness, and consequently supply chain productivity? 


\section{METHODOLOGY}

This study was applied in terms of purpose and correlation in terms of the method of work. At first, the Kolmogorov test was used for normal distribution, and the Pearson correlation test was used. In this research, the internet and library resources have been used to collect information. The standard questionnaire of critical factors of knowledge management in the supply chain designed by

Chang China et al. has been used to measure variables.

\section{Finding}

Demographic

Gender

Table 1. Frequency distribution and percentage of the gender of employees of Calais Dairy Compata

\begin{tabular}{|l|l|r|}
\hline Percentage & Frequency & Gender \\
\hline \hline 68.5 & 37 & Man \\
\hline 31.5 & 17 & Female \\
\hline 100.0 & 54 & Total \\
\hline
\end{tabular}

Table 1 shows respondents' gender shows that out of 54 respondents (high and middle-class managers and staff and staff involved in knowledge management and supply chain in Kale Amol Dairy Products Company), 68.5\% included men, and 31.5\% were women.

Age

Table 2. Frequency distribution of respondents' age

\begin{tabular}{|l|l|r|}
\hline Percentage & Frequency & Age \\
\hline \hline 42.6 & 23 & $25-30$ \\
\hline 38.9 & 21 & $35-31$ \\
\hline 18.5 & 10 & or above36 \\
\hline 100.0 & 54 & Total \\
\hline
\end{tabular}

Table 2 shows the frequency distribution of respondents' age. Experimental findings showed that $42.6 \%$ of respondents were between 25 and 30 years old, the highest percentage was between 31 and 35 years old, and finally, $18.5 \%$ were from 36 years and older. The following is a diagram of the age of respondents.

\section{SERVICE EXPERIENCE}

Table 3. Frequency distribution of respondents' service history

\begin{tabular}{|l|l|r|}
\hline \hline Percentage & Frequency & Service Experience \\
\hline 63.0 & 34 & Under-five years \\
\hline 31.5 & 17 & years 6-10 \\
\hline 5.6 & 3 & years11-15 \\
\hline 100.0 & 54 & Total \\
\hline
\end{tabular}

Table 3 shows the frequency distribution of service history among respondents. The findings indicate that $63 \%$ of respondents have under five years of service experience and are young forces, 31.5\% have between 6 and 10 years of experience and 5.6\% have service experience between 11 and 15 years.

FIELD OF STUDY

Table 4. Frequency distribution and percentage of respondents in terms of field of study

\begin{tabular}{|c|c|c|}
\hline Percentage & Frequency & Field of Study \\
\hline 44.4 & 24 & Technical \\
\hline 55.6 & 30 & Non-technical \\
\hline 100.0 & 54 & Total \\
\hline
\end{tabular}


The Relationship Between the Critical Factors for Knowledge Management in Supply Chain Efficiency Amol's Kalleh Dairy Company

Table 4 shows the status of the field of study of the respondents. Empirical findings show that $44.4 \%$ have the technical field, and $55.6 \%$ have the non-technical field of study.

\section{EDUCATION LEVEL}

Table 5. Frequency distribution and frequency percentage of respondents' education level

\begin{tabular}{||l|l|r||}
\hline Percentage & Frequency & Education Level \\
\hline \hline 55.6 & 30 & Bachelor \\
\hline 40.7 & 22 & Master \\
\hline 3.7 & 2 & PhD \\
\hline 100.0 & 54 & Total \\
\hline
\end{tabular}

Table 5 shows the frequency distribution and frequency of the level of education of the respondents studied. $55.6 \%$ of respondents have a bachelor's degree, the highest number is $40.7 \%$ have postgraduate education, and $3.7 \%$ have doctoral education.

\section{Test hypotheses}

Assumptions derived from research objectives have been formulated based on the assumption of the relationship between research variables. In these tests, the zero H0 hypothesis based on the lack of association between variables and the opposite assumption of H1 is based on the relationship between them. Pearson correlation test [to investigate the relationship between critical factors of knowledge management (organizational strategy, organizational structure, knowledge management team, knowledge audit and knowledge map) and efficiency and effectiveness of supply chain in Kale Amol Dairy Products Company] has been used. Besides,

the statistical level in which the hypothesis was rejected or accepted by SPSS software was 0.05.

It should be noted that the Kolmogorov-Smirnov test has been used as a default test for the Pearson test.

The table below shows the test result of the Kolmogorov-Smirnov test.

Table 6. Kolmogorov-Smirnov test to determine the normality of the data

\begin{tabular}{|r|r|r|r|r|}
\hline Result & Significant level & Kolmogorov & N & Variable \\
\hline Normal & $0 / 20$ & $1 / 067$ & 54 & Organizational Strategy \\
\hline Normal & $0 / 1$ & $1 / 753$ & 54 & Organizational Structure \\
\hline Normal & $0 / 057$ & $1 / 335$ & 54 & Knowledge Management Team \\
\hline Normal & $0 / 15$ & $1 / 560$ & 54 & Knowledge Auditing \\
\hline Normal & $0 / 125$ & $1 / 177$ & 54 & Knowledge Map \\
\hline
\end{tabular}

As the table above shows, according to the reported significance level, the variables of organizational strategy, organizational structure, knowledge management team, knowledge audit and knowledge map have a normal distribution. Assumptions derived from research objectives have been formulated based on the assumption of the relationship between research variables. In these tests, the zero H0 hypothesis based on the lack of association between variables and the opposite assumption of $\mathrm{H} 1$ is based on the relationship between them. Pearson correlation test [to investigate the relationship between critical factors of knowledge management (organizational strategy, organizational structure, knowledge management team, knowledge audit and knowledge map) and efficiency and effectiveness of supply chain in Kale Amol Dairy Products Company] has been used. Besides, the statistical level in which the hypothesis was rejected or accepted by SPSS software was 0.05.

\section{DISCUSSION}

Test the relationship between organization strategy and efficiency:

Research Hypothesis: There is a relationship between the organization's strategy and supply chain efficiency in Kale Amol Dairy

Products Company. 
The Relationship Between the Critical Factors for Knowledge Management in Supply Chain Efficiency Amol's Kalleh Dairy Company

Table 7. The Relationship between Organizational Strategy and Efficiency

\begin{tabular}{|c|c|c|c|}
\hline Performance & Organizational Strategy & \multicolumn{2}{|c|}{ Pearson correlation coefficient } \\
\hline $0 / 388$ & 1 & Pearson correlation & \multirow{3}{*}{$\begin{array}{r}\text { Organizational } \\
\text { Strategy }\end{array}$} \\
\hline $0 / 004$ & & Significant level & \\
\hline 54 & 54 & Total sample number & \\
\hline 1 & $0 / 388$ & Pearson correlation & \multirow{3}{*}{ Performance } \\
\hline & $0 / 004$ & Significant level & \\
\hline 54 & 54 & Total sample number & \\
\hline
\end{tabular}

Considering the calculated significance level (0.004), which is less than 0.05 , it can be concluded that there is a relationship between organizational strategy and efficiency. Therefore, the assumption of H1 is confirmed, and the assumption of H0 is rejected as a result of the hypothesis in question is proved. According to the Pearson correlation coefficient calculated (0.388), which is between 0.2 and 0.4 , it can be concluded that the intensity of correlation between organizational strategy complexity and efficiency is quantitative, besides, due to the positive correlation coefficient of Pearson (+or-), it can be stated that the more the strategy of the organization improves, the more efficiency of the organization will be.

Test the relationship between organizational structure and efficiency

Research hypothesis: There is a relationship between organization structure and supply chain efficiency in Amol Calais Dairy Products Company.

Table 8. The Relationship between Organizational Structure and Efficiency

\begin{tabular}{|r|r|r|r|}
\hline Performance & Organizational Strategy & \multicolumn{2}{|c|}{ Pearson correlation coefficient } \\
\hline $0 / 328$ & 1 & Pearson correlation & \\
\hline $0 / 015$ & & Significant level & Organizational \\
& Strategy \\
\hline 54 & 54 & Total sample number & \multirow{2}{*}{ Performance } \\
\hline 1 & $0 / 328$ & Pearson correlation & \\
\hline 54 & $0 / 015$ & Significant level & \\
\hline & 54 & Total sample number & \\
\hline & & &
\end{tabular}

Considering the calculated significance level (0.015), which is less than 0.05 , it can be concluded that there is a relationship between organizational structure and efficiency. Therefore, the assumption of $\mathrm{H} 1$ is confirmed, and the assumption of $\mathrm{H} 0$ is rejected as a result of the hypothesis in question is proved. Considering the Pearson correlation coefficient calculated (0.328), which is between 0.2 and 0.4 , it can be concluded that the intensity of correlation between organizational structure complexity and efficiency is quantitative, also, due to the positive correlation coefficient of Pearson (+or -), it can be stated that the more the structure of the organization improves, the more the efficiency of the organization.

Test the relationship between knowledge management team and efficiency -

Research hypothesis: There is a relationship between the knowledge management team and supply chain efficiency in Kale Amol

Dairy Products Company.

Table 9. Relationship between Knowledge Management and Efficiency Team

\begin{tabular}{|c|c|c|c|}
\hline Performance & Knowledge & \multicolumn{2}{|c|}{ Pearson correlation coefficient } \\
\hline $0 / 422$ & 1 & Pearson correlation & \\
\hline $0 / 001$ & & Significant level & Knowledge \\
\hline 54 & 54 & Total sample number & Management Team \\
\hline 1 & $0 / 422$ & Pearson correlation & \\
\hline & $0 / 001$ & Significant level & Performance \\
\hline 54 & 54 & Total sample number & \\
\hline
\end{tabular}


Considering the calculated significance level $(0.001)$, which is smaller than 0.05 , it can be concluded that there is a relationship between knowledge management team and efficiency. Therefore, the assumption of $\mathrm{H} 1$ is confirmed, and the assumption of $\mathrm{H} 0$ is rejected as a result of the hypothesis in question is proved.

According to the Pearson correlation coefficient calculated (0.422), which is between 0.4 and 0.6, it can be concluded that the intensity of correlation between the knowledge management team and efficiency is moderate, in addition to the positive Pearson correlation coefficient (+or-) it can be stated that the better the knowledge management team, the better the efficiency of the organization.

Test the Relationship between Organizational Knowledge Audit and Efficiency

Research hypothesis: There is a relationship between auditing organizational knowledge and supply chain efficiency in Kale Amol

Dairy Products Company.

Table 10. The Relationship between Organizational Knowledge Audit and Efficiency

\begin{tabular}{|r|r|r|r|}
\hline Performance & $\begin{array}{r}\text { Auditing Organizational } \\
\text { Knowledge }\end{array}$ & \multicolumn{2}{|c|}{ Pearson correlation coefficient } \\
\hline $0 / 445$ & 1 & Pearson correlation & \multirow{2}{*}{ Auditing Organizational } \\
& & Snowledge \\
\hline $0 / 001$ & 54 & Total sample number & Performance \\
\hline 54 & $0 / 445$ & Pearson correlation & \\
\hline 1 & $0 / 001$ & Significant level & Tnnnnn \\
\hline 54 & 54 & Total sample number & \\
\hline & & &
\end{tabular}

Considering the calculated significance level $(0.001)$, which is less than 0.05 , it can be concluded that there is a relationship between auditing organizational knowledge and efficiency. Therefore, the assumption of $\mathrm{H} 1$ is confirmed, and the assumption of $\mathrm{H} 0$ is rejected as a result of the hypothesis in question is proved. According to the Pearson correlation coefficient calculated (0.445), which is between 0.4 and 0.6, it can be concluded that the intensity of correlation between organizational knowledge audit and efficiency is moderate, also, considering the positive correlation coefficient of Pearson (+or-), it can be stated that the more organizational knowledge audit improves, the better the efficiency of the organization to achieve organizational goals.

Test the relationship between organizational knowledge map and efficiency

Research hypothesis: There is a relationship between knowledge map and supply chain efficiency in Kale Amol Dairy Products

Table 11. The Relationship between Organizational Knowledge Map and Efficiency

Company.

\begin{tabular}{|r|r|r|r|}
\hline Performance & Knowledge Map & \multicolumn{2}{|c|}{ Pearson correlation coefficient } \\
\hline $0 / 465$ & 1 & Pearson correlation & \\
\hline $0 / 000$ & & Significant level & Knowledge \\
& 54 & Total sample number & Map \\
\hline 54 & $0 / 465$ & Pearson correlation & \multirow{2}{*}{ Performance } \\
\hline 1 & $0 / 000$ & Significant level & \\
\hline 54 & 54 & Total sample number & \\
\hline
\end{tabular}

Considering the calculated significance level (0.000), which is less than 0.05 , it can be concluded that there is a relationship between organizational knowledge map and efficiency. Therefore, the assumption of $\mathrm{H} 1$ is confirmed, and the assumption of $\mathrm{H} 0$ is rejected as a result of the hypothesis in question is proved. According to the Pearson correlation coefficient calculated (0.465), which is between 0.4 and 0.6 , it can be concluded that the intensity of correlation between knowledge map and efficiency is moderate, in addition to the positive Pearson correlation coefficient (+or-), it can be stated that the more organizational knowledge map is improved and strengthened, the better the efficiency of the organization to achieve organizational goals.

This section investigates the relationship between critical factors of knowledge management (organizational strategy, organizational structure, knowledge management team, knowledge audit and knowledge map) and effectiveness. 
The Relationship Between the Critical Factors for Knowledge Management in Supply Chain Efficiency Amol's Kalleh Dairy Company

Test the Relationship between Organizational Strategy and Effectiveness

Research hypothesis: There is a relationship between organizational strategy and supply chain effectiveness in Kale Amol Dairy

Products Company.

Table 12. The Relationship between Organizational Strategy and Effectiveness

\begin{tabular}{|c|c|c|c|}
\hline Effectiveness & Organizational Strategy & \multicolumn{2}{|c|}{ Pearson correlation coefficient } \\
\hline $0 / 443$ & 1 & Pearson correlation & \multirow{3}{*}{$\begin{array}{r}\text { Organizational } \\
\text { Strategy }\end{array}$} \\
\hline $0 / 001$ & & Significant level & \\
\hline 54 & 54 & Total sample number & \\
\hline 1 & $0 / 443$ & Pearson correlation & \multirow{3}{*}{ Effectiveness } \\
\hline & $0 / 001$ & Significant level & \\
\hline 54 & 54 & Total sample number & \\
\hline
\end{tabular}

Considering the calculated significance level (0.001), which is less than 0.05, it can be concluded that there is a relationship between organizational strategy and effectiveness. Therefore, the assumption of $\mathrm{H} 1$ is confirmed, and the assumption of $\mathrm{H} 0$ is rejected as a result of the hypothesis in question is proved.

According to the Pearson correlation coefficient calculated (0.443), which is between 0.4 and 0.6 , it can be concluded that the intensity of correlation between organizational strategy and effectiveness is moderate, in addition to the positive Pearson correlation coefficient (+or-), it can be stated that the more organizational process is improved and strengthened, the more influential the organization will be in achieving organizational goals.

Test the relationship between organizational structure and effectiveness

Research hypothesis: There is a relationship between the organization's structure and the effectiveness of the supply chain in Kale Amol Dairy Products Company.

Table 13. The Relationship between Organizational Structure and Effectiveness

\begin{tabular}{|r|r|r|r|}
\hline Effectiveness & Organizational Structure & \multicolumn{2}{|c|}{ Pearson correlation coefficient } \\
\hline $0 / 350$ & 1 & Pearson correlation & \multirow{2}{*}{$\begin{array}{r}\text { Organizational } \\
\text { Structure }\end{array}$} \\
\hline $0 / 01$ & & Significant level & \multirow{2}{*}{ Effectiveness } \\
\hline 54 & 54 & Total sample number & \\
\hline 54 & $0 / 350$ & Pearson correlation & \\
\hline & $0 / 01$ & Significant level & \\
\hline & 54 & Total sample number & \\
\hline
\end{tabular}

Considering the calculated significance level (0.01), which is less than 0.05 , it can be concluded that there is a relationship between organizational structure and effectiveness. Therefore, the assumption of $\mathrm{H} 1$ is confirmed, and the $\mathrm{H} 0$ assumption is rejected as a result of the hypothesis to be proved. According to the Pearson correlation coefficient calculated (0.350), which is between 0.2 and 0.4 , it can be concluded that the intensity of correlation between organizational structure complexity and effectiveness is quantitative, besides due to the positive correlation coefficient of Pearson (+or-), it can be stated that the more the organizational structure improves, the more influential the organization will be.

Test the relationship between the knowledge management team and the effectiveness

Research hypothesis: There is a relationship between the knowledge management team and supply chain effectiveness in Kale Amol

Dairy Products Company.

Table 14. Relationship between Knowledge Management Team and Effectiveness

\begin{tabular}{|c|c|c|c|}
\hline Effectiveness & $\begin{array}{r}\text { Knowledge } \\
\text { Management Team }\end{array}$ & \multicolumn{2}{|c|}{ Pearson correlation coefficient } \\
\hline $0 / 459$ & 1 & Pearson correlation & \multirow{3}{*}{$\begin{array}{r}\text { Knowledge } \\
\text { Management Team }\end{array}$} \\
\hline $0 / 001$ & & Significant level & \\
\hline 54 & 54 & Total sample number & \\
\hline 1 & $0 / 459$ & Pearson correlation & \multirow{3}{*}{ Effectiveness } \\
\hline & $0 / 001$ & Significant level & \\
\hline 54 & 54 & Total sample number & \\
\hline
\end{tabular}


Considering the calculated significance level $(0.001)$, which is smaller than 0.05 , it can be concluded that there is a relationship between knowledge management team and effectiveness. Therefore, the assumption of $\mathrm{H} 1$ is confirmed, and the $\mathrm{H} 0$ assumption is rejected as a result of the hypothesis to be proved.

According to the Pearson correlation coefficient calculated (0.459), which is between 0.4 and 0.6, it can be concluded that the intensity of correlation between the knowledge management team and effectiveness is moderate, in addition to the positive Pearson correlation coefficient (+or-) it can be stated that the better the knowledge management team, the better the effectiveness of the organization.

Test the Relationship between Organizational Knowledge Audit and Effectiveness

Research hypothesis: There is a relationship between auditing organizational knowledge and supply chain effectiveness in Kale Amol Dairy Products Company.

Table 15. The Relationship between Auditing Organizational Knowledge and Effectiveness

\begin{tabular}{|r|r|r|r|}
\hline Effectiveness & $\begin{array}{r}\text { Auditing Organizational } \\
\text { Knowledge }\end{array}$ & \multicolumn{2}{|c|}{ Pearson correlation coefficient } \\
\hline $0 / 465$ & 1 & Pearson correlation & \multirow{2}{*}{$\begin{array}{r}\text { Auditing Organizational } \\
\text { Knowledge }\end{array}$} \\
\hline $0 / 000$ & & Significant level & \\
\hline 54 & 54 & Total sample number & Effectiveness \\
\hline 1 & $0 / 465$ & Pearson correlation & \\
\hline 54 & $0 / 000$ & Significant level & \\
\hline 54 & Total sample number & \\
\hline
\end{tabular}

Considering the calculated significance level $(0.000)$, which is less than 0.05 , it can be concluded that there is a relationship between organizational knowledge auditing and effectiveness. Therefore, the assumption of $\mathrm{H} 1$ is confirmed, and the $\mathrm{H} 0$ assumption is rejected as a result of the hypothesis to be proved.

According to the Pearson correlation coefficient calculated (0.465), which is between 0.4 and 0.6 , it can be concluded that the intensity of correlation between organizational knowledge audit and effectiveness is moderate, also, considering the positive correlation coefficient of Pearson (+or-), it can be stated that the better the organizational knowledge audit, the better the effectiveness of the organization in achieving organizational goals.

Test the relationship between organizational knowledge map and effectiveness

Research hypothesis: There is a relationship between knowledge map and supply chain effectiveness in Kale Amol Dairy Products

Table 16. The Relationship between Organizational Knowledge Map and Effectiveness

Company.

\begin{tabular}{|r|r|r|r|}
\hline Effectiveness & Knowledge Map & \multicolumn{2}{|c|}{ Pearson correlation coefficient } \\
\hline $0 / 499$ & 1 & Pearson correlation & \multirow{2}{*}{ Knowledge Map } \\
\hline $0 / 000$ & & Significant level & \multirow{2}{*}{ Effectiveness } \\
\hline 54 & 54 & Total sample number & \\
\hline 1 & $0 / 499$ & Pearson correlation & \\
\hline 54 & $0 / 000$ & Significant level & \\
\hline & 54 & Total sample number & \\
\hline
\end{tabular}

Considering the calculated significance level $(0.000)$, which is less than 0.05 , it can be concluded that there is a relationship between organizational knowledge map and effectiveness. Therefore, the assumption of $\mathrm{H} 1$ is confirmed, and the $\mathrm{H} 0$ assumption is rejected as a result of the hypothesis to be proved. According to the Pearson correlation coefficient calculated (0.499), which is between 0.4 and 0.6, it can be concluded that the intensity of correlation between knowledge map and efficiency is moderate, also, considering the positive correlation coefficient of Pearson (+or-), it can be stated that the more organizational knowledge map is improved and strengthened, the better the effectiveness of the organization in achieving organizational goals. 
The Relationship Between the Critical Factors for Knowledge Management in Supply Chain Efficiency Amol's Kalleh Dairy Company

Determining the priority of variables using the Friedman test -4-3

Table 17. Friedman test for determining the priority of variables in terms of mean

\begin{tabular}{|l|l|l|}
\hline \multicolumn{1}{|c|}{ Variables in order of priority } & \multicolumn{1}{|}{ Average ratings by 5} & \\
& Knowledge Map & \multirow{3}{*}{$01 / 0$} \\
\cline { 1 - 2 } Knowledge Management Team & 3.27 & \\
\cline { 1 - 2 } & 3.26 & \\
\hline Oudit & 3.09 & \\
\cline { 1 - 2 } Organizational Structure & 3.00 & \\
\hline
\end{tabular}

Considering the significant level obtained that is less than 0.05 , it can be concluded that the research variables are different in terms of average, and the averages indicate that knowledge map, knowledge management team, auditing, organizational structure and ultimately corporate strategy have the highest standards.

\section{CONCLUSION}

As mentioned in this research, we considered two main hypotheses, and for each of the five sub-hypotheses based on critical factors of knowledge management (organizational strategy, organizational structure, knowledge management team, knowledge audit and knowledge map) that the main hypotheses were: 1. There is a relationship between critical factors of knowledge management and supply chain efficiency in Kale Amol Dairy

Products Company.

Describing the Relationship between Organizational Strategy and Supply Chain Efficiency The organizational strategy variable in the research mentioned in the second chapter is one of the critical factors of knowledge management that significantly impacts organizations' success, especially in their efficiency. In this research, according to the hypothesis test, there is a positive relationship between organization strategy and supply chain efficiency and this hypothesis was confirmed. Therefore, in Amol Calais Dairy Products Company, improving the organizational system leads to supply chain efficiency.

Describing the relationship between organizational structure and supply chain efficiency Organizational structure variable in the research mentioned in the second chapter is one of the critical factors of knowledge management that significantly impacts organizations' success, especially in their efficiency. In this research, there is a positive relationship between organizational structure and supply chain efficiency according to the hypothesis test, and this hypothesis was confirmed. Therefore, in Amol Calais Dairy Products Company, improving the organizational structure leads to the supply chain's efficiency.

Describing the relationship between the knowledge management team and supply chain efficiency The knowledge management team's variable in the research mentioned in the second chapter is one of the critical factors of knowledge management that significantly impacts organizations' success, especially in their efficiency. In this research, according to the hypothesis test, there is a positive relationship between knowledge management team and supply chain efficiency and this hypothesis was confirmed. Therefore, in Amol Calais Dairy Products Company, improving the knowledge management team leads to the supply chain's efficiency.

Describing the Relationship between Organizational Knowledge Audit and Supply Chain Efficiency The organizational knowledge audit variable in the second chapter's research is one of the critical factors of knowledge management that significantly impacts organizations' success, especially in their efficiency. In this research, there is a positive relationship between organizational knowledge audit and supply chain efficiency according to the hypothesis test, and this hypothesis was confirmed. Therefore, in Amol Calais Dairy Products Company, improving knowledge audit leads to supply chain efficiency.

Describing the Relationship between Organizational Knowledge Map and Supply Chain Efficiency The organizational knowledge map variable in the research mentioned in the second chapter is one of the critical factors of knowledge management that significantly impacts organizations' success, especially in their efficiency. In this research, according to the hypothesis test, there is a positive relationship between organizational knowledge map and supply chain efficiency and this hypothesis was confirmed. Therefore, in Amol Calais Dairy Products Company, improving the executive knowledge map leads to supply chain efficiency.

2. There is a relationship between critical factors of knowledge management and supply chain effectiveness in Kale Amol Dairy

Products Company.

Describing the Relationship between Organizational Strategy and Supply Chain Effectiveness The organizational strategy variable in the research mentioned in the second chapter is one of the critical factors of knowledge management that significantly impacts organizations' success, especially in their effectiveness. In this research, there is a positive 


\section{The Relationship Between the Critical Factors for Knowledge Management in Supply Chain Efficiency Amol's Kalleh Dairy Company}

relationship between organizational strategy and supply chain effectiveness according to the hypothesis test, and this hypothesis was confirmed. Therefore, in Amol Calais Dairy Products Company, improving corporate strategy leads to supply chain effectiveness.

Describing the Relationship between Organizational Structure and Supply Chain Effectiveness Organizational structure variable in the research mentioned in the second chapter is one of the critical factors of knowledge management that significantly impacts organizations' success, especially in their effectiveness. In this research, there is a positive relationship between organizational structure and supply chain effectiveness according to the hypothesis test, and this hypothesis was confirmed. Therefore, in Amol Calais Dairy Products Company, improving the organizational structure leads to the supply

chain. Describing the relationship between knowledge management team and supply chain effectiveness The knowledge management team's variable in the research mentioned in the second chapter is one of the critical factors of knowledge management that significantly impacts organizations' success, especially in their effectiveness. In this research, according to the hypothesis test, there is a positive relationship between the knowledge management team and supply chain effectiveness and this hypothesis was confirmed. Therefore, in Amol Calais Dairy Products Company, improving the knowledge management team leads to the supply chain's effectiveness.

Describing the Relationship between Organizational Knowledge Auditing and Supply Chain Effectiveness The organizational knowledge audit variable in the second chapter's research is one of the critical factors of knowledge management that significantly impacts organizations' success, especially in their effectiveness. In this research, according to the hypothesis test, there is a positive relationship between organizational knowledge audit and supply chain effectiveness and this hypothesis was confirmed. Therefore, in Amol Calais Dairy Products Company, improving corporate knowledge audit leads to supply chain

effectiveness.

Describing the relationship between organizational knowledge map and supply chain effectiveness The organizational knowledge map variable in the research mentioned in the second chapter is one of the critical factors of knowledge management that significantly impacts organizations' success, especially in their effectiveness. In this research, according to the hypothesis test, there is a positive relationship between organizational knowledge map and supply chain effectiveness and this hypothesis was confirmed. Therefore, in Amol Calais Dairy Products Company, improving the executive knowledge map leads to supply chain effectiveness.

\section{Reference}

1. Chang, Tsung-Han- Wang, Tien-Chin, Using the fuzzy multi-criteria making approach for measuring the possibility of successful knowledge management, Information sciences, An international journal, Vol.179,2009.

2. Darroch J, Mc Naughton R, Examining the link between knowledge management practices \& types of innovation, Journal of intellectual capital, Vol.3. No.3,2010.

3. Akhavan, $P \&$ et al., Identification of knowledge management critical success factors in Iranian academic research centres, Education, Business and Society: Contemporary Middle Eastern Issues, Volr. No. ₹,2009.

4. Hult, G. T. M \& et al., Strategic supply chain management: Improving performance through a culture of competitiveness and knowledge development, Strategic Management Journal, Vol. 28,2007.

5. Akhavan, P. and Jafari, M, Critical issues for knowledge management implementation at a national level, The Journal of Information and Knowledge Management Systems, Vol. r૫, No. ',2006.

6. Akhavan, P. and Jafari, M, Critical issues for knowledge management implementation at a national level, The Journal of Information and Knowledge Management Systems, Vol. זч, No. ',2006.

7. Wu, C, Knowledge creation in a supply chain, Supply Chain Management: An International Journal, Vol.13, No3,2008.

8. Wang. C\& et al., A conceptual case-based model for knowledge sharing among supply chain members, Business Process Management Journal, Vol.14,2008.

9. Wong, K.Y, Critical success factors for implementing knowledge management in small and medium enterprises, Industrial management \& Data systems, Vol.105, No.3,2005.

10. Marwick, Kiessling, Exploring knowledge management to organizational performance outcomes in a transitional economy, Journal of world business, Vol.44,2009.

11. Sotriakoa, Tatiana- Mary, Zeppou, MATE model: A strategic knowledge management technique on the chessboard of public- sector modernization, Management decision, Vol.42,2004.

12. Tiwana, A. The knowledge management Toolkit: Practical techniques for building a knowledge management system, New Jersey: Prentice-Hall,2007.

13. Broadberry a.Stephen N., Irwin.Douglas A, Labor productivity in the United States and the United Kingdom during the nineteenth century, Explorations in Economic History, Vol. 43,2006. 
The Relationship Between the Critical Factors for Knowledge Management in Supply Chain Efficiency Amol's Kalleh Dairy Company

14. Fernandez, Irmabecerra- Leidner, Dorothy, Knowledge management: An evolutionary view, Advances in management information systems, 2008 .

15. Gatora, N. The evaluation of logistics and the management discipline's supply chain, Springer,1995.

16. Chang, Tsung-Han- Wang, Tien-Chin, Using the fuzzy multi-criteria making approach for measuring the possibility of successful knowledge management, Information sciences, An international journal, Vol.179,2009.

17. Dalkir, Kimiz, Knowledge management in theory and practice, Elsevier butter worth-Heinemann publications,2005. 